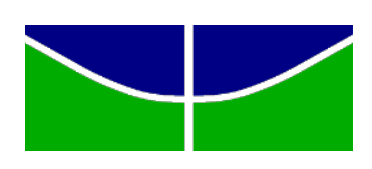

UNIVERSIDADE DE BRASÍLIA

FACULDADE DE CIÊNCIAS DA SAÚDE CURSO DE FARMÁCIA

SIMONE WENSE DIAS AKONTEH

A IDENTIFICAÇÃO DE PLANTAS MEDICINAIS NA EDUCAÇÃO INFANTIL- ELABORAÇÃO DE EXSICATAS COMO FERRAMENTA DE APRENDIZAGEM

BRASÍLIA, DF 


\section{A IDENTIFICAÇÃO DE PLANTAS MEDICINAIS NA EDUCAÇÃO INFANTIL- ELABORAÇÃO DE EXSICATAS COMO FERRAMENTA DE APRENDIZAGEM}

Trabalho de Conclusão de Curso apresentado como requisito parcial para obtenção do grau de Bacharel em Farmácia, na Universidade de Brasília, Faculdade de Ciências da Saúde.

Orientadora: Profa. Dra. Silvia Ribeiro de Souza

BRASÍLIA, DF 


\section{DEDICATÓRIA}

A todas as crianças do mundo, em especial, a minha filha. 


\section{AGRADECIMENTOS}

A Deus, pelo dom da vida, amor incondicional e por ter me orientado ao caminho das plantas medicinais.

A minha família querida, pelo amor e suporte em todos os momentos.

As amizades de longos anos como as "amigas amadas" e as "humildas".

As amizades que foram construídas durante o curso: os farmafriends!

A minha orientadora que sempre me incentivou nas minhas pesquisas.

Aos professores e supervisores de estágio que durante esses anos contribuíram para meu crescimento profissional e pessoal.

Aos grupos de amigos que se fortalecem na agroecologia, produção orgânica, dinâmicas cooperativas e ecopedagogia: Turma Unida Pró-Agoecologia - TUPA, Coletivo Orgânico e Coletivo Sete Saberes.

A todos que ainda preservam a sabedoria do uso das plantas medicinais.

A todos que de alguma forma contribuíram para a realização deste trabalho. 


\section{RESUMO}

O estudo das plantas medicinais na educação infantil necessita de ferramentas lúdicas que tornem o processo de aprendizagem mais prazeroso. Uma das formas de abordagem para a identificação das plantas medicinais é a utilização de exsicatas que, além de ser uma metodologia acessível, permite a percepção sensorial das plantas pelas crianças. Este trabalho teve como objetivo fazer uma revisão de estudos sobre plantas medicinais na educação infantil com ênfase na elaboração de exsicatas, mostrando algumas práticas que podem se relacionar a essa metodologia, como o plantio de hortas medicinais, o desenho, a música, as histórias e poesias. Como modelo experimental, foi elaborado um herbário lúdico com 14 exsicatas de diferentes espécies que pode ser utilizado em sala de aula para o ensino de plantas medicinais. Os resultados mostraram que a elaboração de exsicatas e as demais práticas relacionadas a essa metodologia tiveram um ótimo resultado no processo de aprendizagem das crianças que, se motivaram a participarem das atividades e aprenderam sobre a preservação da biodiversidade local.

Palavras - chave: plantas medicinais, ervas medicinais, educação infantil, exsicatas, herbário. 


\begin{abstract}
The study of medicinal plants in early childhood education requires playful tools that make the learning process more enjoyable. One ways of approaching the identification of medicinal plants is in the use of exsicatas (specimen vouchers) which, besides being an accessible methodology, allows for the sensory perception of plants by children. The objective of the current work is to review studies on medicinal plants in children 's education, with emphasis on the elaborate use of exsicatas (specimen vouchers) that show practices that can be related to this methodology, including for instance: the planting of medicinal gardens, drawings, music, story telling, and poetry. As an experimental model, a ludic herbarium was created with 14 exsicatas (specimen vouchers) with different species that can be used in the classroom for the teaching of medicinal plants. The results show that the preparation of exsicatas (specimen vouchers) and other related practices provide excellent results in the learning process of children who are often motivated to participate in such activities and learn about the preservation of local biodiversity.
\end{abstract}

Key words: medicinal plants, medicinal herbs, children's education, herbarium specimens, herbarium. 


\section{LISTA DE FIGURAS}

Figura 1: Material Vegetal sendo prensado e prensa de madeira com material incluído.

Figuras 2 e 3: Herbário fechado e aberto com uma exsicata.

Figuras 4 e 5: Criança manuseando o herbário com plantas medicinais.

Figura 6: Teatro de fantoches com as crianças.

Figura 7: Sementeiras produzidas pelas crianças.

Figura 8: Jardineiras com as mudas de plantas medicinais e aromáticas.

Figura 9: Capa do livro elaborado pelas professoras da escola com registros das experiências dos alunos.

Figura 10: Livro aberto com fotos de uma criança tomando chá com a família. 


\section{LISTA DE ABREVIATURAS E SIGLAS}

ANPPS: Agenda Nacional de Prioridades de Pesquisa em Saúde

ANVISA: Agência Nacional de Vigilância Sanitária

CERPIS: Centro de Referência em Práticas Integrativas em Saúde

CIATs: Centros de Informação e Assistência Toxicológica

LDBE: Lei de Diretrizes e Bases da Educação

MEC: Ministério da Educação

OMS: Organização Mundial de Saúde

ONU: Organização das Nações Unidas

PNAF: Política Nacional de Assistência Farmacêutica

PNCTIS: Política Nacional de Ciência, Tecnologia e Inovação em Saúde

PNEA: Política Nacional de Educação Ambiental

PNES: Programa Nacional de Escolas Sustentáveis

PNPICS: Política Nacional de Práticas Integrativas e Complementares no SUS

PNPMF: Política Nacional de Plantas Medicinais e Fitoterápicos

RENAFITO: Relação Nacional de Plantas Medicinais e Fitoterápicos

RENISUS: Relação Nacional de Plantas Medicinais de Interesse ao SUS

RCNEI: Referencial Curricular Nacional para a Educação Infantil

SEED: Secretaria de Estado de Educação/ PR

UNB: Universidade de Brasília

UNESCO: Organização das Nações Unidas para Educação, Ciência e Cultura 


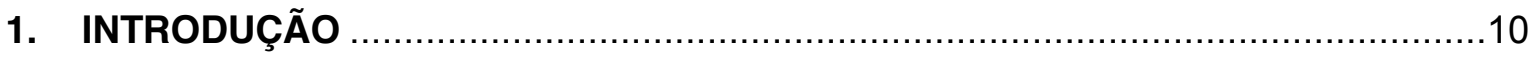

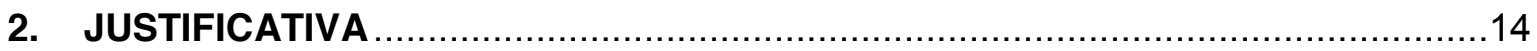

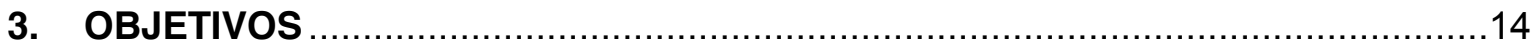

4. METODOLOGIA

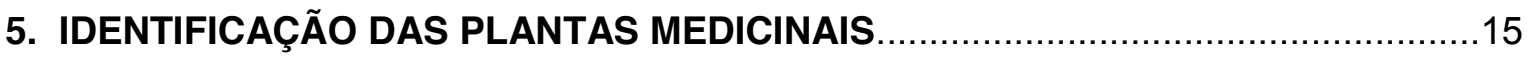

5.1 Plantas medicinais na educação infantil.....................................................

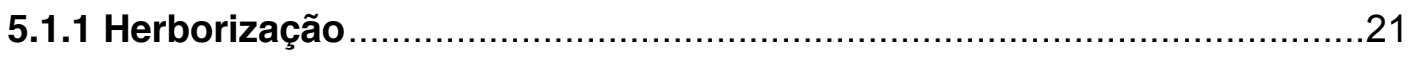

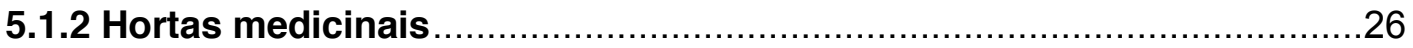

5.1.3 Plantas medicinais no desenho, música e história infantil....................31

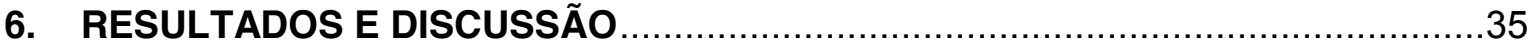

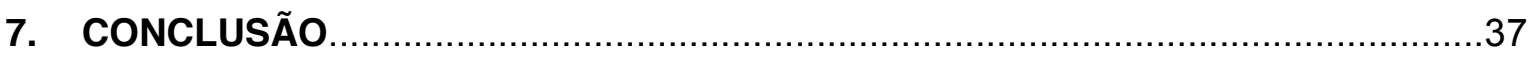

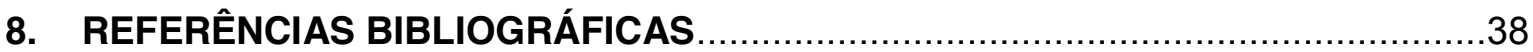




\section{INTRODUÇÃO}

Os remédios à base de ervas são considerados as formas mais antigas de cuidados com a saúde conhecidos pela humanidade, estando presente na realidade da maioria da população mundial (AMBROSE et. al., 2016; VEIGA JUNIOR et al., 2005). O Brasil possui grande potencial para a produção de fitomedicamentos (BRASIL, 2006; CALIXTO, 2003) por ser o país de maior biodiversidade do mundo (BFG, 2015; BRASIL, 2010; CALIXTO, 2003) com uma população que tem a tradição do uso das ervas medicinais tanto nativas quanto introduzidas (LORENZI e MATOS, 2008).

Muitas espécies ainda são usadas empiricamente, sem respaldo cientifico quanto à sua eficácia e segurança, o que demonstra que existe uma enorme lacuna entre a oferta de plantas e as poucas pesquisas (FOGLIO, et al., 2006). Informações sobre a forma de preparo, as indicações e restrições de uso de cada espécie são os requisitos de qualidade definidos nas normas específicas para farmácias de manipulação e farmácias vivas e estão contidas nas Farmacopéias (BRASIL, 2011).

Nesse sentido, por meio do Ministério da Saúde, políticas públicas como a Política Nacional de Assistência Farmacêutica- PNAF; a Política Nacional de Ciência, Tecnologia e Inovação em Saúde- PNCTIS; a Agenda Nacional de Prioridades de Pesquisa em Saúde- ANPPS; a Política Nacional de Práticas Integrativas e Complementares no SUSPNPICS e a Política Nacional de Plantas Medicinais e Fitoterápicos- PNPMF (Decreto ${ }^{\circ}$ $5.813 / 2006$ ) estabelecem responsabilidades, diretrizes e linhas prioritárias para o desenvolvimento de ações que incluam a fitoterapia e a utilização das plantas medicinais no SUS (BRASIL, 2006).

As ações decorrentes da PNPMF se expressam no Programa Nacional de Plantas Medicinais e Fitoterápicos que, dentre outras atribuições desse programa, está a de atualizar as listas de plantas medicinais do SUS: a Relação Nacional de Plantas Medicinais de Interesse ao SUS - RENISUS e a Relação Nacional de Plantas Medicinais e Fitoterápicos- RENAFITO (BRASIL, 2009). A PNPMF visa melhorar o acesso da população às plantas medicinais e medicamentos fitoterápicos que, devem ter nas suas 
cadeias produtivas, a participação da agricultura familiar e o uso sustentável da biodiversidade brasileira com inclusão social e regional, valorizando e preservando o conhecimento das comunidades tradicionais e indígenas, além do desenvolvimento industrial e tecnológico nacional (BRASIL, 2006).

Sob a legislação da Secretaria de Vigilância Sanitária, o farmacêutico é o profissional responsável pela formulação de um fitoterápico que deve ser desenvolvido com base na biodiversidade brasileira, abrangendo espécies vegetais nativas e exóticas adaptadas, priorizando as necessidades epidemiológicas da população (BRASIL, 2006). O farmacêutico também deve realizar e divulgar estudos sobre plantas medicinais e fitoterápicos abordando educação em saúde, organização, gestão e desenvolvimento da assistência farmacêutica, incluindo as ações da atenção farmacêutica que promove o uso seguro desses medicamentos pela população (BRASIL, 2006).

Os medicamentos de forma geral, sintéticos (na sua maioria) e vegetais, aparecem como segundo maior agente causador de intoxicações nos registros dos Centros de Informação e Assistência Toxicológica- CIATs, ficando atrás somente dos "agrotóxicos de uso agrícola" (que diferem dos "agrotóxicos de uso doméstico"). Ao se observar a relação de todos os agentes tóxicos com a faixa etária dos indivíduos afetados, as crianças de 1 a 4 anos são as que mais têm registros de intoxicação representando $20,54 \%$ de todos os casos registrados em 2012; 22,90 \% dos casos de 2013 e 25,50\% dos casos de 2014 (19.919 casos). Este último ano, é relativo aos últimos registros disponíveis que se tem acesso até o momento (SINITOX, 2014). Sabe-se, porém que estes dados são subestimados, uma vez que essas informações dependem da participação da população envolvida na notificação dos casos aos CIATs, o que muitas vezes não acontece.

Segundo Monseny et al. (2015), citado por Campos et al.(2016), o envenenamento humano ocasionado por plantas é menos documentado. Em muitos dos casos os sintomas observados não são associados à utilização ou exposição a uma determinada planta sendo notificados como exposição a "agente tóxico desconhecido". 
Pinillos (2003) destaca que esses envenenamentos são frequentes e acontecem por ingestão ou contato com espécies tóxicas que não foram identificadas corretamente ou que foram consumidas em excesso. Durante suas brincadeiras, as crianças são atraídas por pequenos frutos coloridos que são levados à boca. Isto ocorre principalmente nos domicílios, praças, escolas e parques. Quando chegam ao hospital, é rara a associação dos sintomas de intoxicação ao produto ingerido o que torna o diagnóstico etiológico ainda mais difícil (PINILLOS, 2003). Segundo Tavares et al. (2013), o comportamento exploratório e a baixa percepção de risco das crianças são fatores que favorecem essa alta incidência de intoxicação.

Contudo, este "comportamento exploratório" citado pelo autor, pode ser direcionado para uma investigação científica orientada por meio de aulas em que se aborde a temática das plantas medicinais, apoiada em recursos didáticos que estimulem os sentidos das crianças. As atividades lúdicas proporcionam ao aluno uma aprendizagem mais prazerosa, possibilitando a introdução de conceitos como os relativos

à identificação das plantas medicinais, de forma que sua utilização ocorra com o conhecimento dos seus riscos e benefícios.

O simples reconhecimento dessas plantas na educação infantil, fase em que a criança está exposta a um maior risco de intoxicação, assume grande importância para o seu desenvolvimento integral, que depende tanto dos cuidados relacionais afetivos como dos cuidados com os aspectos biológicos do corpo, ou seja, com a sua saúde. Dessa forma, as condutas ocorrem de acordo com os princípios pedagógicos indissociáveis contidos no Referencial Curricular Nacional para a Educação Infantil- RCNEI: "educar, cuidar e brincar" (BRASIL, 2009).

Neste contexto, este trabalho visa discorrer sobre a prática da elaboração de exsicatas que além da sua importância na identificação das plantas medicinais, possibilita vincular diversas outras atividades lúdicas que podem ser realizadas na educação infantil na aprendizagem sobre plantas medicinais. Para este trabalho, foi realizada uma revisão 
bibliográfica sobre o assunto e a elaboração de um herbário que permite às crianças aprenderem na observação e manuseio das exsicatas.

\section{JUSTIFICATIVA}

O presente trabalho teve como motivação o estudo de ferramentas que possam ser utilizadas na educação infantil para o ensino sobre plantas medicinais assim como a pesquisa de trabalhos que demonstrem essa experiência em diversos contextos sociais do Brasil.

\section{OBJETIVOS}

Incentivar o ensino de plantas medicinas na educação infantil por meio da elaboração de exsicatas.

Elaborar a montagem de um herbário lúdico que possibilite o contato das crianças às espécies secas catalogadas de forma a estimular os seus sentidos durante a aprendizagem.

\section{METODOLOGIA}

A pesquisa ocorreu durante o período de agosto a novembro de 2017 e consistiu na revisão bibliográfica de trabalhos sobre a utilização de exsicatas e as atividades relacionadas à herborização na educação infantil, que tinham como abordagem as plantas medicinais. A pesquisa ocorreu em dois seguimentos: foram utilizadas as bases de dados, Scielo e Portal Capes com os termos: educação infantil, exsicata, herbário e plantas medicinais para pesquisas em periódicos, resumos e anais de congressos compreendidos entre o período de 2003 a 2017, para trabalhos que demonstrassem a parte experimental. O outro estudo correspondeu à pesquisa para basear a teoria abordada nas definições de termos, legislações e outros fundamentos em publicações e livros da área da saúde. 
Como projeto experimental, foi desenvolvido um herbário lúdico que teve seu início em 2016 e hoje contém 14 espécies de plantas que são na sua maioria, medicinais. O objetivo do herbário consiste em se ter um material didático a partir do qual as espécies medicinais estejam disponíveis por meio de exsicatas inseridas de forma a permitir seu manuseio pelas crianças.

\section{IDENTIFICAÇÃO DAS PLANTAS MEDICINAIS}

O termo plantas medicinais é usado para descrever toda ou partes de uma espécie vegetal (cultivadas ou não) que são utilizadas para prevenir, tratar e curar doenças (AMBROSE et. al., 2016; BRASIL, 2012). Suas propriedades terapêuticas vêm ao longo da história sendo utilizadas em todos os continentes dentre as mais variadas culturas (LORENZI e MATOS, 2008).

O Brasil, por abrigar diversos povos imigrantes, herdou com eles a tradição do uso de suas plantas que logo foram incluídas em sua medicina juntamente àquelas nativas. Dessa forma, se torna muitas vezes difícil para a população diferenciar quais plantas são nativas e quais são introduzidas, bem como diferenciar suas propriedades e efeitos adversos.

O trabalho de identificar corretamente as espécies medicinais consiste na comparação com uma espécie já descrita e é feita a cada vez que se deseja conhecer o nome de um ser coletado ou encontrado na natureza, proporcionando segurança e eficácia ao tratamento fitoterápico (MENTZ e BORDIGNON, 2003).

Justifica-se a preocupação dos fitoterapeutas com a botânica, já que, uma caracterização empobrecida da planta pode levar a enganos letais (LORENZI e MATOS, 2008). Cada espécie vegetal tem algumas características exclusivas e, por isso, o termo espécie, está relacionado à unidade vegetal. Quando várias características são comuns a várias espécies, elas são agrupadas em um mesmo gênero que juntos, compõem as famílias botânicas. Nos sistemas atuais, além das estruturas reprodutivas e vegetativas, as características anatômicas, embriológicas e químicas são consideradas em um 
mesmo nível de importância na delimitação desses táxons (espécies, gêneros,...) (MENTZ e BORDIGNON, 2003).

$\mathrm{Na}$ caracterização de uma espécie, para sua determinação ou identificação, usualmente se inicia por observar as estruturas maiores, macroscópicas. Assim, observase de modo geral, as características externas: como é a sua morfologia desde a ramificação da raiz, forma do caule, forma e disposição das folhas (filotaxia) e organização e composição das flores e frutos sendo esses últimos, muito importantes para a identificação da espécie (MENTZ e BORDIGNON, 2003).

Como esse conhecimento exige a constante observação da flora, é fácil perceber porque se torna uma sabedoria de povos que estão em contanto constante com a natureza, mesmo nos dias de hoje.

É impressionante a sabedoria, muito mais profunda, que o ameríndio acumulou desde época recuada; número imponente de vegetais usados por diferentes tribos sulamericanas revelou, a luz da experimentação exata nos laboratórios, ponderável atividade farmacodinâmica ou, pelo menos, substâncias químicas definidas. Aí estão as plantas curarizantes, o toé, a coca, o tabaco, o guaraná, os timbós, e muito mais. Mario Guimarães Ferri [..] disse, não sem razão, que, no Brasil, a Botânica começou com o silvícola; e Barbosa Rodrigues demonstrou que a nomenclatura fitológica teve início com os Tupis (RIZZINI e MORS, 1976).

Outro aspecto importante na sistematização é a uniformização da nomenclatura botânica que evita ambiguidades que são recorrentes devido, sobretudo, às características regionais (OLIVEIRA e AKISUE, 1998). Por outro lado, elas são úteis e importantes em trabalhos etnobotânicos como fonte de informações sobre a cultura e vocabulário de uma população, podendo dar indícios sobre a utilização popular de uma espécie na região (MENTZ e BORDIGNON, 2003).

Muitas plantas foram batizadas considerando seus usos medicinais ou propriedades que foram sendo descobertas por populações nativas já que, a classificação das espécies ocorreu inicialmente de forma empírica (LORENZI e MATOS, 
2008; OLIVEIRA e AKISUE, 1998). Desse modo, muitas espécies foram descritas depois de já fazerem parte das Farmacopéias oficiais e, em função disso, ao serem posteriormente descritas pela botânica, passaram a receber o epíteto especifico officinale, sendo conhecidas até hoje com este nome (LORENZI e MATOS, 2008).

A nomenclatura, é um dentre os aspectos da botânica, difícil de se assimilar, segundo relato de alunos do ensino fundamental e médio, momento em que, muitas vezes, estão entrando em contato com esse assunto pela primeira vez (NUNES et al., 2016; LOUREIRO e DAL-FARRA, 2015). Nesse contexto, as aulas são no geral, somente expositivas e visam transmitir o conteúdo de forma teórica (BRAZ e LEMOS, 2014; FAGUNDES e GONZALEZ, 2006) passando a ser visto pelos alunos como algo distante da sua realidade, o que gera desinteresse no tema (NUNES et al, 2015).

Contudo, é demonstrado como uma abordagem mais significativa e que conduza os alunos a ter contato com o ambiente natural (objeto de estudo), proporciona maior interesse e melhor assimilação de termos botânicos aos alunos que se motivam na realização das atividades propostas (NUNES et al., 2015; OTA, 2012; FAGUNDES e GONZALEZ, 2006).

Esta é uma realidade que fica bem clara quando falamos sobre educação infantil que, na sua essência, necessita de meios mais lúdicos para realização de suas atividades, sendo o momento que muito se aprende através das brincadeiras planejadas (BRASIL, 2009). Essa abordagem permite que as informações possam ser assimiladas aos poucos e de forma prazerosa, colaborando no desenvolvimento das crianças.

\subsection{Plantas medicinais na educação infantil}

Segundo o Ministério da Educação- MEC, a Educação Infantil é a primeira etapa da Educação Básica e tem como finalidade o desenvolvimento integral da criança de 0 a 5 anos, em seus aspectos físico, afetivo, intelectual, linguístico e social, complementando a ação da família e da comunidade - Lei no 9.394/96, art. 29 (BRASIL, 2009). 
O seu currículo visa promover o desenvolvimento integral dessas crianças por práticas que articulem as suas experiências e seus saberes com os conhecimentos do patrimônio cultural, artístico, ambiental, científico e tecnológico (BRASIL, 2009).

O ensino sobre plantas medicinais tem ganhado cada vez mais espaço nessa etapa aparecendo nos conteúdos de aulas de educação ambiental, saúde e sustentabilidade que estão cada vez mais presentes nas escolas e creches, públicas e particulares.

"Espiral de ervas e plantas medicinais" compõem a lista de ações que podem ser desenvolvidas por escolas públicas, com o financiamento do Programa Nacional Escolas Sustentáveis- PNES, que apoia projetos voltados à melhoria da qualidade de ensino de forma a tornar as escolas espaços educadores sustentáveis (BRASIL, 2013).

As ações do PNES se apoiam na Política Nacional de Educação Ambiental- Lei № 9795/99, em sintonia com os princípios e diretrizes do Tratado de Educação Ambiental para Sociedades Sustentáveis e Responsabilidade Global, a Carta da Terra, a Carta das Responsabilidades Humanas e a Agenda 21, documentos estes que legitimam e fundamentam a Educação Ambiental (BRASIL, 2017).

Percebemos então, que a temática das plantas medicinais vai além da área da saúde, pois, por se tratar de terapêutica natural, abrange questões ambientais, na relação das pessoas com a natureza. Mesmo na educação do campo, indígena e quilombola, presentes em comunidades que naturalmente tem em sua tradição a ligação com a terra, acontecem trabalhos para o resgate dessa sabedoria.

Lomeu e locca (2016), por meio de discussões nos conteúdos de Ciências, abordaram a temática "Plantas Medicinais" com 20 crianças de uma turma de Educação Infantil (de 5 e 6 anos) da Escola Rural do município de Terra Nova do Norte- MT.

Esta atividade proporcionou a elas, assimilar as informações debatidas, relacionando-as com as situações rotineiras ou a um acontecimento da sua vida que envolveu o uso de alguma planta medicinal, para aliviar alguma dor, enfermidades ou simplesmente o plantio (Lomeu e locca, 2016). 
Ao entrar em contato com seus conhecimentos a criança assimila e integra os novos de maneira não arbitrária e não literal, construindo novos conhecimentos (LOMEU E IOCCA, 2016).

Maldaner (2016) teve como foco abordar a educação indígena Guarani e as práticas escolares do Colégio Estadual Indígena Teko Ñemoingo em São Miguel do Iguaçu- PR. Em seu estudo, observou que:

No processo de aprendizagem pelas crianças Kaiowá na aldeia Laranjeira Ñanderu, elas aprendem muito na convivência com seus pais e irmãos e na relação entre si, não apenas aspectos educacionais da relação familiar, mas principalmente da relação dos ensinamentos com a natureza, com relação às plantas medicinais, nos cuidados de se caminhar e manter na mata e na hora da caçada (MALDANER, 2016).

Segundo o autor, há uma relação forte dos indígenas Guarani com as plantas relacionadas aos chás, plantas medicinais e raízes, sabedoria essa que pode ser resgatada pelo colégio estadual indígena da região e aliada a uma prática de conhecimentos científicos, como por exemplo, na preparação dos chás (MALDANER, 2016).

Em uma entrevista com o Chamoi (rezador) João Ramos da Aldeia Ocoy, este citou algumas plantas que poderiam ser ensinadas na escola indígena, para conhecimento dos alunos: Coropê, Boldo nativo, Guine ou pipi (MALDANER, 2016).

A escola tem uma contribuição bem específica na aprendizagem, sendo de acordo com Polhasto (2017), o lugar onde o aluno vivencia diariamente a diversidade cultural no contato com os professores, colegas e outras pessoas ali presentes. A escola é um ambiente privilegiado, em que as crianças trazem suas experiências e também levam dela as vivências que são transmitidas então às suas famílias, criando redes de conhecimento (POLHASTO, 2017).

Esse aprendizado que relaciona o ambiente escolar com a família foi relatado por Dal Soto (2013), com uma turma de pré- escola. As crianças foram desafiadas a fazerem uma pesquisa questionando aos pais, avós, tios, entre outros, quais as plantas 
medicinais que eles utilizam, e para qual finalidade. Em seguida, levaram para a sala de aula amostras das plantas para compartilharem o relato com os colegas e, a partir disso, cada criança construiu e organizou um álbum para si.

"Percebe-se que envolver as crianças em projetos de trabalho e pesquisa significa permitir-Ihes um melhor reconhecimento de si mesmas e do mundo. O estímulo da pesquisa, observação e questionamento, instigou e incentivou as crianças na construção do conhecimento, tornando-as mais críticas, participativas e motivadas na busca de novas aprendizagens (DAL SOTO, 2013)".

A botânica surgiu da investigação, experimentação dos estudiosos e, neste caso, as crianças, fazem o mesmo trabalho com seu espírito investigativo. De acordo com Lomeu e locca (2016), diversas atividades podem estar em consonância com as que são de investigação, porém, elas devem apresentar características que viabilizam este processo, pois, se trabalhadas de forma desordenadas e descontextualizadas, essas atividades descaracterizam a investigação.

Neste sentido, para ocorrer algum tipo de conhecimento, é preciso antes que o material a ser apreendido seja relacionável à estrutura cognitiva do aprendiz (LOMEU e IOCCA, 2016). Partindo deste ponto de vista, temos o ensino- aprendizagem como algo que deva ser construído a partir da realidade de cada criança.

Antes de qualquer tentativa de discussão de técnicas, de materiais, de métodos para uma aula dinâmica assim, é preciso, indispensável mesmo, que o professor se ache "repousado" no saber de que a pedra fundamental é a curiosidade do ser humano. É ela que me faz perguntar, conhecer, atuar, mais perguntar, reconhecer (FREIRE, 2007 p.86).

Em seu estudo, Dal Soto (2013), observou que os conhecimentos de algumas crianças, ao serem socializados, geraram inquietação e questionamentos em outros colegas, que buscam construir o seu entendimento do assunto. "Com isso, percebe- se que é possível transformar um conhecimento individual, já estabelecido, em uma necessidade de aprendizagem no grupo, através da socialização e das trocas propostas e mediadas pelo professor." 
Tem-se, assim, a relevância das interações sociais na sala de aula, no que diz respeito à construção do conhecimento. Vygotsky (1998), explica que o processo de aprendizagem está relacionado à mediação, pela intervenção do professor ou pelos próprios colegas, os quais têm um papel fundamental no desenvolvimento individual (DAL SOTO, 2013).

$\mathrm{Na}$ educação infantil, o processo de aprendizagem e interação com o ambiente acontece através das atividades lúdicas. Segundo Lourenço e Brito Junior (2017), a atividade lúdica pode ser uma brincadeira, um jogo ou qualquer outra atividade que ao visar interação, proporciona a experiência completa do momento, associando o ato, o pensamento e o sentimento.

\subsubsection{Herborização}

Qualquer estudo envolvendo plantas medicinais deve ser iniciado pela amostragem botânica. Para tanto, um material testemunho exsicata (deriva da palavra latina exsico, que quer dizer secar) deve ser preparado. Este material consiste em um ramo da planta, de preferência fértil (ou seja, com flores e/ou frutos), que é prensado, seco e acondicionado em uma coleção científica denominada "herbário" (LORENZI e MATOS, 2008). Identificar, colher e preservar o material botânico requerem metodologias especificas de acordo com a estrutura e o habitat dos vegetais.

Após identificação da espécie, realiza-se a coleta que se refere ao ato de se retirar uma ou mais plantas inteiras ou parte delas, e deve incluir a preocupação com a possibilidade de a planta alvo ser o único exemplar da região, com risco de extinção (MENTZ e BORDIGNON, 2003). No geral as coletas são realizadas no período da manhã, pois o sol não está tão quente de forma que possa prejudicar estruturas mais delicadas como flores que podem vir a cair (INCT, 2013). Contudo, o horário não deve ser tão cedo ao ponto que ainda haja orvalho na superfície das plantas, o que dificulta o processo de secagem (CORRÊA JÚNIOR e SCHEFFER, 2013). 
Dentre as plantas coletadas, é recomendável pegar mais de uma amostra de cada espécie para depositá-la em um herbário local que possa identifica-la corretamente. Os herbários nacionais estão localizados em jardins botânicos, universidades e outras instituições de pesquisa (MENTZ e BORDIGNON, 2003).

É importante que, junto com a espécie coletada, estejam as suas informações anotadas durante a coleta que incluem: a altura da planta, condições do terreno, nome do coletor, número de coleta, temperatura, data e horário da coleta. Registrar informações como coloração das folhas e flores são de grande importância, pois, após a secagem e o tempo de armazenamento, essas características são mudadas (INCT, 2013).

O material da coleta é disposto entre papéis absorventes (geralmente utiliza- se folhas de jornal) de forma que a planta fique visualmente com a aparência final que se deseja ter: mostrando as estruturas mais importantes a serem observadas para sua identificação. Procura- se estender folhas e flores para que não fiquem dobradas ou enrugadas (MENTZ e BORDIGNON, 2003) lembrando, de se manter as folhas da planta com as partes adaxial e abaxial visíveis (superior e inferior), assim como as flores e gemas, inserção e disposição das folhas, etc. Dessa forma, se obtém uma amostra que serve de referência para comparação com outras plantas que se deseja identificar.

As amostras montadas precisam de uma estrutura que as mantenham firmes durante o processo de secagem e, para isso, utiliza-se papelão intercalado com as amostras que estão entre os jornais. Todo este conjunto então, e colocado em uma prensa que, geralmente é feita de madeira, como na Figura 1.

A secagem dessas amostras ocorre através de estufa a 60 graus quando 0 objetivo é apenas a conservação para comparação (INCT, 2013) ou a 37 graus quando se deseja obter material da amostra para análise sem perder componentes mais voláteis.

Após a secagem, as amostras são catalogadas em papéis cartonados para ficarem dispostas a consulta em um herbário. As informações que foram anotadas na hora da coleta são inseridas em uma etiqueta padronizada presente em cada exsicata. Mesmo se observando todo o processo de herborização, essas amostras não ficam 
imunes a pragas sendo necessárias medidas de que a preservem como o uso de conservantes e baixas temperaturas (INCT, 2013).
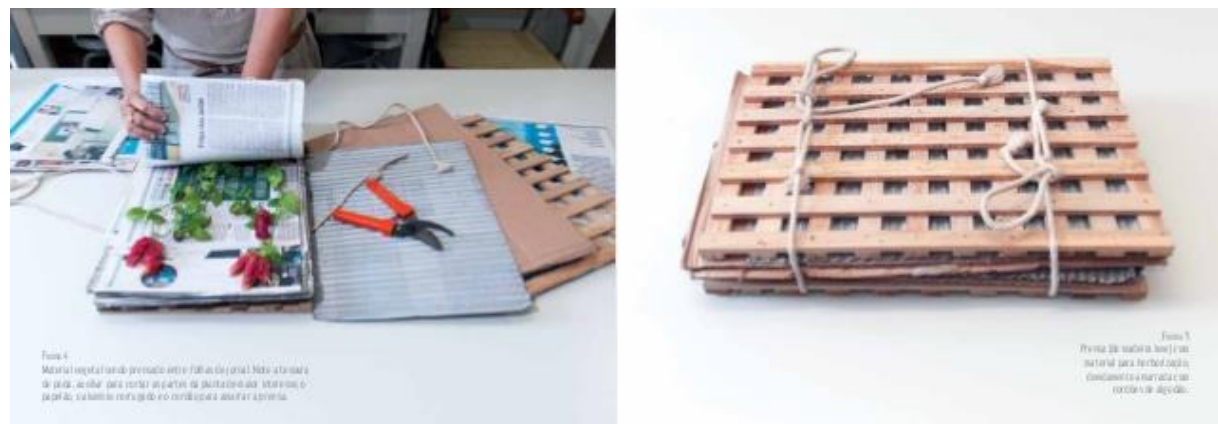

Figura 1: Material vegetal sendo prensado e prensa de madeira com material incluído (INCT, 2013).

O herbário pode servir como ferramenta a ser utilizado nas aulas de Botânica em todos os graus de escolaridade (SANTOS, 2003; STACE, 1980). Essa coleção de plantas representa a realidade da escola ou em volta dela e mesmo, nos quintais das casas dos alunos, permitindo conhecer e conservar a biodiversidade local (GONZATTI, SCUR e SCOPEL, 2017; BRAZ e LEMOS, 2014; FAGUNDES e GONZALEZ, 2006) e propiciar o estudo desse material na escola (LOUREIRO e DAL-FARRA, 2015).

O trabalho intitulado "Meu primeiro Herbário: Descobrindo as plantas medicinais" (AKONTEH e SOUZA, 2016) proporcionou a pesquisa sobre plantas que são popularmente encontradas e cultivadas na região do Distrito Federal- DF e que, na sua maioria, contém propriedades medicinais já relatadas em bibliografia.

As espécies foram selecionadas pela sua localização, tendo origem nos ambientes que me são mais comumente frequentados, como o próprio quintal, quintal de vizinhos e amigos, o parque Olhos D’Água, a Universidade de Brasília-UnB e a cidade de Cavalcante- GO, gerando 14 exsicatas: (Alternanthera brasiliana (L.) O. Kunt (penicilina); Abutilon striatum (lanterna chinesa); Bauhinia forficata Link. (pata de vaca); Cajanus cajan (L.) Millsp. (feijão guandu); Emilia sonchifolia (L.) DC. (serralhinha); Hibiscus rosasinensis L. (hibisco vermelho); Lavandula sp. (rosmaninho); Lippia alba (Mill) N. E. Brown. (erva cidreira); Ocimum gratissimum L. (alfavaca- cravo); Ocimum selloi Benth (manjericão); Salvia officinalis L. (sálvia); Tetradenia riparia (Hochst.) Codd. (falsa mirra); 
Vernonia ruficoma Schltdl. ex Mart. (assa- peixe) e Anacardium humile A. St.-Hil. (cajuzinho do cerrado).

A seleção das amostras também se deu pela presença de flores e frutos nas espécies que foram coletadas e secadas a partir dos métodos usuais de herborização. A partir das amostras já secas, foi elaborado um catálogo demonstrativo que pode ser facilmente reproduzido e utilizado em sala de aula. As páginas foram feitas com um tipo de papelão que deve ser firme o suficiente para que as amostras possam manter sua forma sem se quebrar e cada espécie foi inserida com cola branca em uma página contendo no seu lado inferior direito, os dados da coleta Figuras 2 e 3.
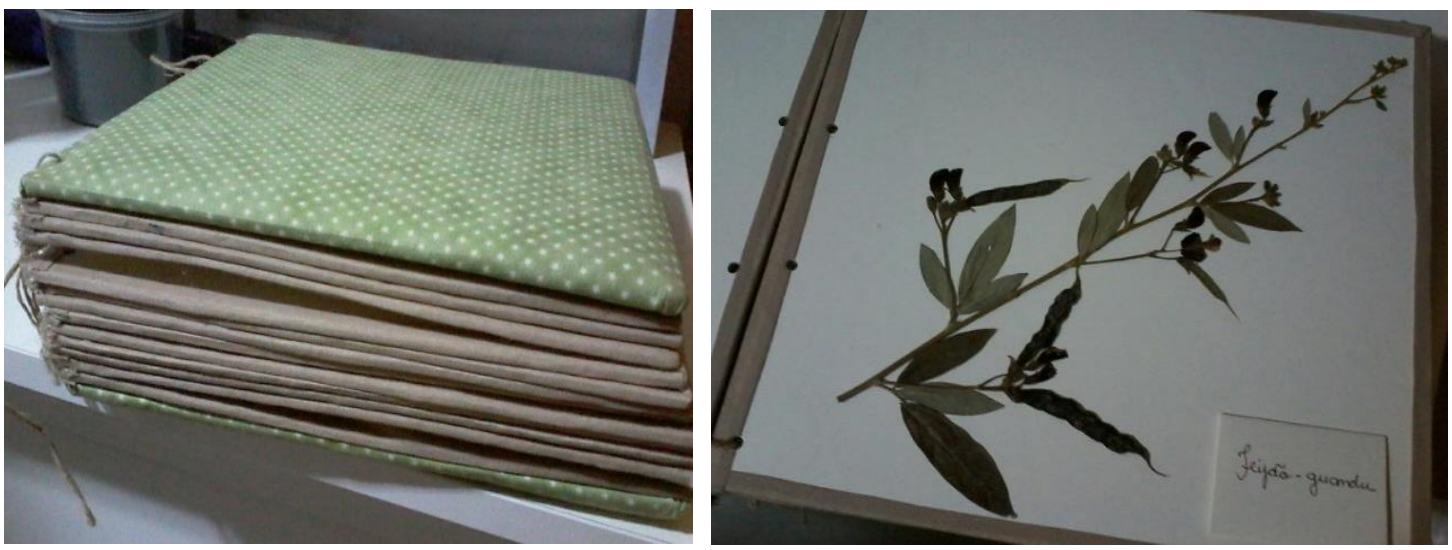

Figuras 2 e 3: Herbário fechado e aberto com uma exsicata.

Todo o processo foi feito manualmente sendo que, para a encadernação, se utilizou uma corda de sizal, permitindo assim a inclusão de novas amostras na coleção. Com intuito que a aprendizagem ocorra de forma mais lúdica, foram inseridos elementos como pintura e um extrato da Lavandula sp. Figuras 4 e 5.
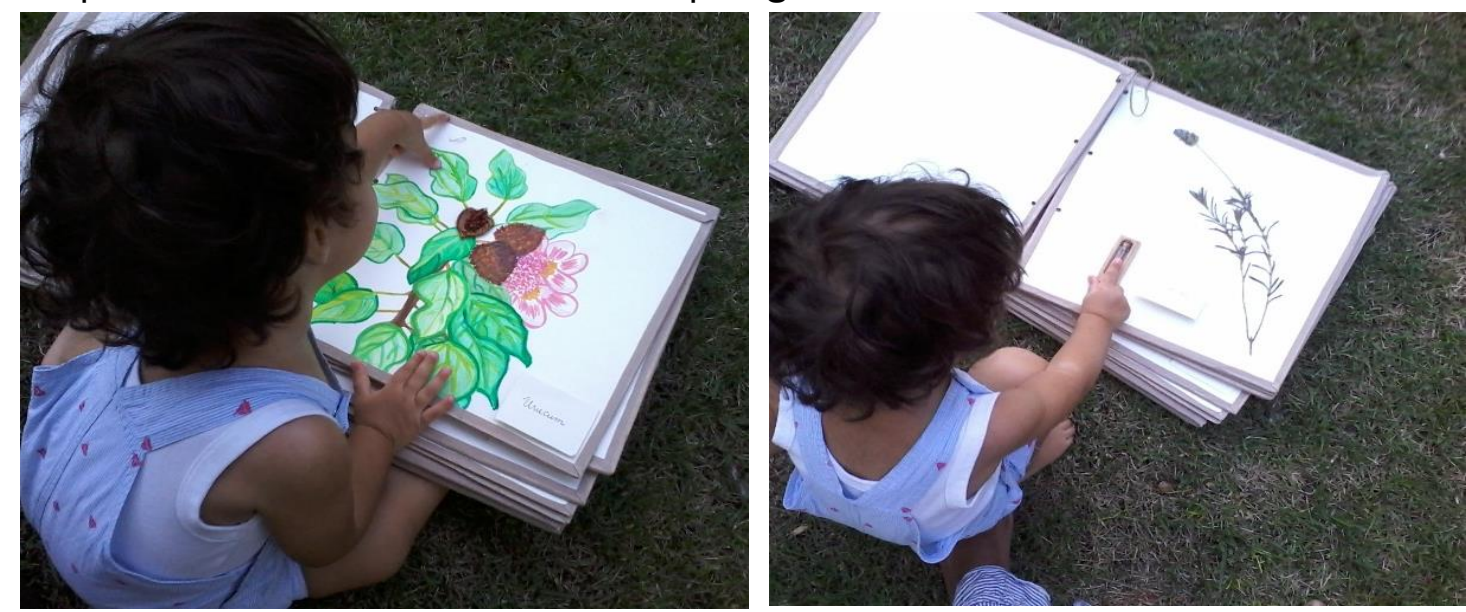

Figuras 4 e 5: Criança manuseando o herbário com plantas medicinais. 
Nos primeiros anos da educacao infantil, pode-se introduzir a prática da herborização de uma forma que as próprias crianças participem do processo adaptando-o para uma atividade mais simples e lúdica, com colagens de flores, folhas e sementes secas em sala de aula.

Esta foi uma das atividades mencionadas no trabalho de Sousa (2013), na abordagem do tema das plantas medicinais junto às crianças da educação infantil e ensino fundamental na Escola dos Sonhos, em Florianópolis - SC.

As práticas realizadas junto aos alunos foram elaboradas respeitando a capacidade cognitiva por faixa etária. Enquanto que se trabalhou com os alunos do $5^{\circ}$ ano a importância e confecção do herbário, com as crianças do ensino infantil- do jardim 1 ao jardim 5 (1 a 6 anos), foram desenvolvidas as atividades de colagem de flores e folhas secas (SOUSA, 2013).

As espécies de camomila, macela, erva-cidreira, calêndula, e folhas frescas de alecrim que foram utilizadas para se transmitir o assunto das plantas medicinais foram oferecidas uma de cada vez, para que eles pudessem apreciar cuidadosamente o cheiro, a textura, observar a forma e a coloração de cada planta (SOUSA, 2013). Cada aluno foi orientado a realizar a colagem de forma a compor um vestido, o "vestido de Laura" de uma poesia que foi trabalhada com as crianças e que será relatada mais a frente (SOUSA, 2013).

Em outro momento, essas mesmas espécies foram utilizadas pelas crianças para a confecção de mini- travesseiro aromático, atividade em que todas elas participaram e concluíram com interesse. Conforme a UNESCO (2005), as práticas que lidam com os sentidos, como o tato são fundamentais nessa fase do aprendizado infantil (SOUSA, 2013).

As amostras coletadas para as atividades podem ser provenientes de diversos locais, porém, quando tem origem em locais de convivência dos alunos, eles demonstram maior interesse pela atividade, como foi observado por Fagundes e Gonzalez (2006), que 
estudaram o comportamento de alunos da $2^{\mathrm{a}}$ série do ensino médio (período noturno) no Colégio Estadual Deputado Arnaldo Faivro Busato, do município de Pinhais-PR.

Durante a atividade escolar que envolvia a coleta de plantas medicinais, foi percebido que os alunos se motivaram pela pesquisa na comunidade por causa da ligação afetiva que esses locais representam para eles como sua casa, casa de parentes ou de vizinhos (FAGUNDES e GONZALEZ, 2006).

Essa percepção de que os alunos se interessaram pelas plantas medicinais já conhecidas deles foi também observada no trabalho de Carmo et al.,(2013) com o $6^{\circ}$ ano do ensino fundamental da Escola Municipal Maria Martins de Carvalho, no município de Russas- CE.

Os alunos, em número de 20 , se reuniram em duplas (cada dupla com uma espécie) para coletar, prensar e secar as espécies do horto de plantas medicinais da escola. Depois da secagem, eles prepararam as exsicatas com a sua devida identificação para a construção de um herbário escolar de plantas medicinais que favoreceu a eles, a aprendizagem de botânica (CARMO et al.,2013).

Os trabalhos que envolvem atividades com plantas medicinais e crianças, geralmente envolvem também a etapa do plantio na construção de hortas medicinais. $\mathrm{Na}$ educação infantil, o plantio se mostra um momento de grande interesse por parte das crianças. Além de permitir a convivência com as plantas medicinais, a horta que muitas vezes está presente na escola, tem papel fundamental para os processos de herborização por ser a fonte da matéria prima estudada.

\subsubsection{Hortas medicinais}

É o espaço destinado ao plantio de mudas e sementes medicinais e que pode ter formatos variados como "espiral de ervas" ou "horta- mandala medicinal" estando ou não,

consorciadas com outras plantas. É fundamental que seja orgânica, sem a utilização de agrotóxicos em nenhuma etapa da produção. Deve-se usar adubação orgânica que pode 
ser feita a partir de um composto que utiliza restos de alimentos e material vegetal da própria horta (PAIXÃO, HUMBERTO e OLIVEIRA, 2013).

Em sua elaboração, pode-se aproveitar de materiais reutilizáveis como pneus para delimitar os canteiros, garrafas pets para fazer um sistema de irrigação e caixas de leite para fazer plaquinhas com os nomes das plantas.

O local escolhido deve permitir o livre acesso para seu cuidado contínuo, estando perto do seu cuidador como no próprio quintal, que, segundo Amorozo (2007), são áreas ao redor dos domicílios que ocupam uma posição especial, visto que são locais de acesso imediato para onde se transplantam elementos úteis da vegetação nativa.

Indo além do quintal de casa, o plantio medicinal é uma das atividades que mais envolvem a comunidade, pois, tanto para sua elaboração como manutenção, necessita de mão de obra, que requer muitas vezes presença dos pais, professores e alunos.

Em contrapartida, sendo um meio que gera vida, permite que a comunidade envolvida se beneficie das ervas que podem ser colhidas e, ainda com a sua criação, presenteia com a possibilidade de se restaurar ou aproveitar espaços que muitas vezes ficam abandonados, sendo depósitos para lixo e causando risco a saúde.

Esta necessidade de se aproveitar espaços físicos ociosos, foi percebido na Creche Municipal Professora Virgínia Marília Mello, em Manaus- AM, aonde se desenvolveu um projeto de extensão que deu origem a uma "horta agroecológica" com a participação coletiva das crianças, professores, pais e colaboradores na produção de hortaliças e demais plantas, buscando qualidade de vida na produção de alimentos saudáveis (LOURENÇO e BRITO JUNIOR, 2017).

Os canteiros foram feitos de forma bem lúdica, com formatos diferenciados para atrair a atenção e interação das crianças da creche que tiveram a oportunidade de regar, limpar e colher algumas espécies medicinais e aromáticas como manjericão (Ocimum basilicum L.), hortelã (Mentha spicata. L.), alecrim (Rosmarinus officinalis L.), manjerona (Origanum majorana L.) e capim santo (Cymbopogon citratus (DC.) Stapf ) (LOURENÇO e BRITO JUNIOR, 2017). 
Para nortear as ações do projeto, foi adotado um roteiro de atividades que facilitasse a mediação da abordagem do tema trabalhado, permitindo que os pais e estudantes se apropriassem das atividades planejadas de plantio de mudas e construção da horta (LOURENÇO e BRITO JUNIOR, 2017).

O estudo de Feng e Ferrante (2008), acompanhou a realidade escolar da educação rural na escola Hermínio Pagotto, que atende alunos de $1^{a}$ à $8^{a}$ série e está localizada no assentamento rural Bela Vista em Araraquara, interior de São Paulo.

Ao trabalhar com crianças do ensino fundamental em uma horta escolar, foram plantadas bálsamo, boldo do chile, salgueiro, hortelã e a novalgina. Além dos valores relativos à preservação e valoração das propriedades naturais e medicinais que cada planta possui, foi possível a elas associar a este cultivo valores como custo agregado e facilidade de manutenção, conceitos que podem ser introduzidos às crianças nesta etapa de ensino (FENG e FERRANTE, 2008).

Além da aprendizagem que ocorre na hora do plantio e manutenção, a horta medicinal também proporciona a elaboração de outras atividades relacionadas, pois, é através dela que se tem a matéria prima para estudo: a planta medicinal.

Depois de coletada, é possível a elaboração de herbários, fabricação de produtos fitoterápicos, de limpeza, cosméticos, repelentes, travesseiros aromáticos, chás e sucos terapêuticos, elaboração de receitas pela escola, etc (FENG e FERRANTE, 2008)

A escola que foi objeto de estudo de Bezerra (2012), Escola Vivência Infantil, Lazer e Aprendizagem (Vila), localizada em Fortaleza- CE, atende crianças do berçário ao ensino fundamental e dispõem de uma Farmácia Viva, aonde os alunos conhecem todas as plantas medicinais da escola, seu nome científico, suas utilidades e diferentes modos de preparo (chás, unguentos, lambedores, cremes capilares).

Os alunos fazem os canteiros, plantam e acompanham o crescimento das ervas, fazem xaropes e utilizam as plantas como compressas, chás, etc. As hortaliças e árvores frutíferas também são observadas pelas crianças nos laboratórios de Horta, de Jardim e de Saúde e Alimentação, permitindo o plantio de sementeiras, o estudo nutricional dos 
alimentos, a observação do tempo de floração e frutificação e a coleta e preparo de pratos, polpas, doces e geléias (BEZERRA, 2012).

As atividades dos laboratórios são desenvolvidas com frequência por todos os alunos da escola e o enfoque é proporcionar um aprendizado mais voltado para a prática.

Os alunos pesquisam características e benefícios de uma determinada erva no laboratório de Farmácia Viva, depois vão à cozinha - adaptada para as crianças - e preparam e bebem o chá; em outra atividade do mesmo laboratório, estudam outra erva, preparam sachês aromáticos e costuram integrando aulas de artesanato. Também são feitos xaropes e compressas (BEZERRA, 2012).

Foram realizadas atividades semelhantes de integração ao tema das plantas medicinais no estudo de Sousa (2013), que foi mencionado anteriormente no tópico de "Herborização". Como primeiro passo, sua pesquisa visou conhecer as percepções das crianças sobre as plantas medicinais.

A metodologia utilizada com as crianças da educação infantil se deu pela apresentação de uma sequência de imagens de algumas espécies (hortelã, babosa, camomila, capim limão, tanchagem, melissa, limoeiro, maracujá, laranjeira e goiabeira) destacando as partes utilizadas para fins medicinais, como flores e folhas (SOUSA, 2013).

Das 10 imagens de plantas apresentadas aos jardins, 8 foram reconhecidas por eles. As espécies frutíferas tiveram os maiores percentuais de reconhecimento sendo associadas na maioria das vezes ao uso na alimentação, com a fruta in natura, ou na forma de suco ou tempero. A hortelã, a babosa, a camomila e o capim-limão também foram reconhecidos como espécies medicinais pelos alunos dos jardins de infância (SOUSA, 2013).

A partir da contextualização desse tema com as crianças, buscou-se priorizar como atividade o plantio de mudas na "mandala", privilegiando a visualização e presença de plantas medicinais (alecrim, funcho, camomila, menta e melissa). Essa prática foi realizada com os alunos dos jardins 1 e 2, pois, segundo a autora, nesta fase eles são 
muito táteis e estão em processo de construção do desenvolvimento da coordenação motora. Com intuito que as crianças observassem as diferentes formas de plantio, foi realizada a semeadura de sementes de camomila e o plantio da cavalinha através de estacas da sua planta mãe que já estava na mandala (SOUSA, 2013).

O plantio de mudas é um trabalho que demonstrou ser muito prazeroso para a faixa etária de 1 a 3 anos. $E$, embora eles não tenham a capacidade cognitiva para realizar essa tarefa sozinhos, eles demonstravam bastante interesse e prazer, esboçando sorrisos a cada mudinha plantada (SOUSA, 2013).

As crianças do jardim também tiveram a oportunidade de degustar um chá de erva doce. As mais novas (do jardim 1) foram as que demonstraram maior interesse, sendo que, apenas uma não quis experimentar. Elas demonstraram que gostaram, através das mãozinhas esticadas pedindo para repetir (SOUSA, 2013).

O uso dos sentidos através das plantas medicinas, como na degustação de um chá, percepção dos aromas e texturas das plantas, permite elaborar atividades de inclusão às pessoas que tenham baixa visão e/ou cegueira.

Segundo Cintra (2014) ao se buscar criar condições de igualdade, é necessário primeiro compreender quais são essas condições para que a educação possa realmente ser inclusiva, contemplando todo e qualquer sujeito, independente de sua necessidade educacional. A educação inclusiva no Brasil é uma demanda pedagógica legítima prevista na lei que estabelece as diretrizes e bases da educação (LDBE- Art.59 da Lei $n^{\circ}$ 9.394/1996).

Em seu trabalho, Cintra (2014) teve como objetivo selecionar um grupo de espécies para serem utilizadas na construção de um "jardim sensorial", voltado à prática da educação inclusiva para estudantes cegos e/ou com baixa visão. O espaço escolhido foi o Laboratório Verde no bloco seis do Centro Universitário de Brasília- UniCEUB (CINTRA, 2014).

Sua pesquisa foi por espécies que fossem adequadas para garantir a acessibilidade e inclusão desses estudantes e com isso, foram excluídas as plantas que 
possuíam substâncias que pudessem irritar as mucosas ou que tivessem superfícies perfuro cortantes (CINTRA, 2014).

As espécies também deveriam ter que se adaptar a pequenas áreas, devido ao jardim ser disposto de forma vertical, com as plantas em nichos nas paredes do prédio. Este modelo pode ser reproduzido e aplicado em espaços urbanos, reduzidos e/ou verticais (CINTRA, 2014).

Foram então selecionadas como potenciais para compor o jardim sensorial : Alecrim (R.officinalis), Lavanda (L. dentada L.), Stévia (S. rabaudiana), Gerânio ( $P$.hortorum) e Manjericão (O. basilicum L.) de acordo com suas morfologias bem como estrutura física, convidando o estudante a usar os sentidos do tato, paladar e olfato como forma de perceber as características de cada planta (CINTRA, 2014).

\subsubsection{Plantas medicinais no desenho, música e história infantil}

Uma das atividades mais comuns em salas de aula da educação infantil é a prática do desenho que, segundo Feng e Ferrante (2008), continua sendo frequentemente utilizada em estudos nas áreas da Educação e da Psicologia.

No estudo de Lomeu e locca (2016), já mencionado anteriormente no tópico de "plantas medicinais na educação infantil", utilizou-se o desenho infantil e a apresentação oral das crianças com o intuito de avaliar a contribuição das atividades experimentais que ocorreram a partir da contextualização do tema "Plantas Medicinais".

A abordagem trouxe para a sala de aula diversas possibilidades de se trabalhar diferentes conceitos, como a estrutura das plantas, suas características, composição, nutrição, nomenclatura básica, etc (LOMEU e IOCCA, 2016).

Conforme Goldberg et al. (2005), o desenho permite que a criança possa organizar informações e suas experiências. As expressões traduzidas por meio destas produções indicam o que os estudantes consideram mais importante no ambiente, se constituindo em um "feedback" para o professor (LOUREIRO e DAL-FARRA, 2015). 
Outra forma de expressão artística sempre presente na escola é a música. Segundo Lomeu e locca (2016), através da cantiga "Alecrim", as crianças da educação infantil foram motivadas a aprender brincando sobre a morfologia das plantas, em especial das plantas medicinais.

Em outra atividade, levaram de casa plantas medicinais que eram utilizadas por seus familiares, vinculando os conhecimentos científicos aos saberes populares, o que viabilizou e facilitou a construção de conceitos científicos e não apenas a transmissão desses (LOMEU e IOCCA, 2016).

Polhasto (2017) em seu projeto que teve por tema "Plantas medicinais e aromáticas: uma oportunidade ecopedagógica" realizado com duas turmas do $5^{\circ}$ ano de duas escolas municipais de Foz do Iguaçu- PR, pretendeu levantar informações sobre as plantas medicinais e aromáticas utilizadas pela comunidade, seu conhecimento e interesse por parte dos educadores sobre o assunto.

Apesar do trabalho não ter sido realizado com crianças da educação infantil, a autora sugere levar pessoas mais idosas para conversar com as crianças em sala de aula, uma prática que é bem aceita por crianças do ensino infantil.

Em sua análise, Polhasto (2017) percebeu que a vasta sabedoria cultural e regional presentes em pessoas idosas se mostra nas referências feitas pelas crianças em sala de aula que mencionam os conhecimentos e/ou hábitos adquiridos no ambiente familiar, provenientes especialmente dos avós.

O letramento por histórias e poesias, permite ensinar às crianças na fase anterior a alfabetização, conforme UNESCO (2005). Por meio de uma poesia adaptada a versos que citavam as plantas medicinais, Sousa (2013), elaborou uma atividade em que as crianças dos jardins 3, 4 e 5 conseguiram memorizar o nome de todas as plantas e fazer inferência sobre o uso medicinal de algumas delas.

A atividade consistia em contar a poesia de Cecília Meireles, chamada "O Vestido de Laura", adaptada a versos que citam as plantas medicinais e o seu respectivo uso. 
Em seguida, as crianças foram questionadas para ver se haviam entendido a história e se podiam lembrar-se das plantas citadas e seu uso (SOUSA, 2013):

O vestido de Laura

É de três babados,

Todos bordados.

O primeiro, todinho, todinho

De flores de camomila

Bom para os olhos e para a barriguinha.

No segundo, tem alecrim,

Para sarar a dor

E a febre sim.

O terceiro, folhas de manjericão

Bom para o estômago

Não doer não.

O vestido de Laura,

Vamos ver agora,

Sem mais demora!

Que plantinhas secam

Camomilas e flores

Perdem suas cores.

Se não formos depressa,

Acabou- se o vestido

Que estava florido! (SOUSA, 2013).

As plantas medicinais nas histórias infantis também fizeram parte do projeto "Cheiro do Saber" (SOUZA et. al, 2014) que teve sua primeira edição no Colégio Batista de Brasília- CBB, com turmas do matutino e vespertino do jardim (idade de 5 anos).

Na história intitulada: "Um gostoso e cheiroso chá" foi relatado como o "papai urso" ficava doente e seu filho fazia um chá para ele se recuperar. Neste contexto, as crianças puderam relatar as suas próprias experiências no uso dos chás medicinais com suas famílias (SOUZA et. al, 2014). 
As crianças também participaram das atividades de pintura, vídeo, plantio e teatro de fantoches Figuras 6, 7 e 8.
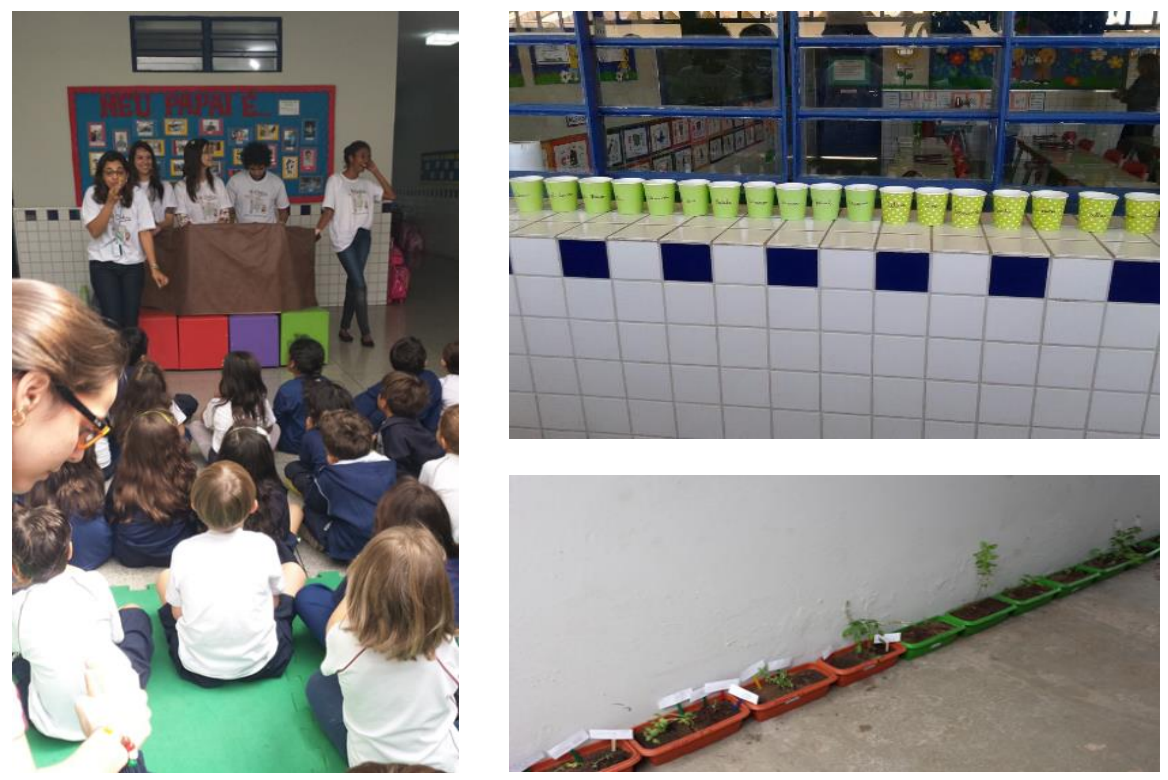

Figuras 6, 7 e 8: Teatro de fantoches com as crianças; sementeiras na janela da sala de aula; jardineiras com mudas de plantas medicinais e aromáticas.

Para a atividade do plantio foram utilizadas sementes e mudas. A sementeira foi feita a partir de copinhos com terra que ficavam na janela da sala de aula para cada criança cuidar e molhar sua semente (SOUZA et. al, 2014).

O plantio de mudas teve como intuito criar um jardim sensorial para as crianças composto por espécies medicinais e aromáticas que foram doadas pelo Centro de Referência em Práticas Integrativas em Saúde- CERPIS. Na hora do plantio, as crianças formaram duplas para plantarem nas jardineiras (SOUZA et. al, 2014).

Ao final do projeto, as professoras de cada turma produziram um livro sobre a história "Um gostoso e cheiroso chá" que foi contada incluindo os registros das atividades feitas pelos alunos e fotos de cada criança junto à família tomando chá Figuras 9 e 10.

O projeto "Cheiro do Saber" foi criado a partir do projeto de extensão "Chá com Prosa" pela necessidade de se alcançar o público infantil nas conversas sobre plantas medicinais (SOUZA et. al, 2014). 
O "Chá com prosa", foi desenvolvido com professores e alunos da faculdade de farmácia da UnB no Centro de Saúde II do Itapoã- DF, com o intuito de trocar saberes com a população local sobre o conhecimento das plantas medicinais, assim como orientar sobre suas indicações e segura utilização através de uma conversa que terminava com todos tomando algum chá medicinal (SOUZA et. al, 2014).
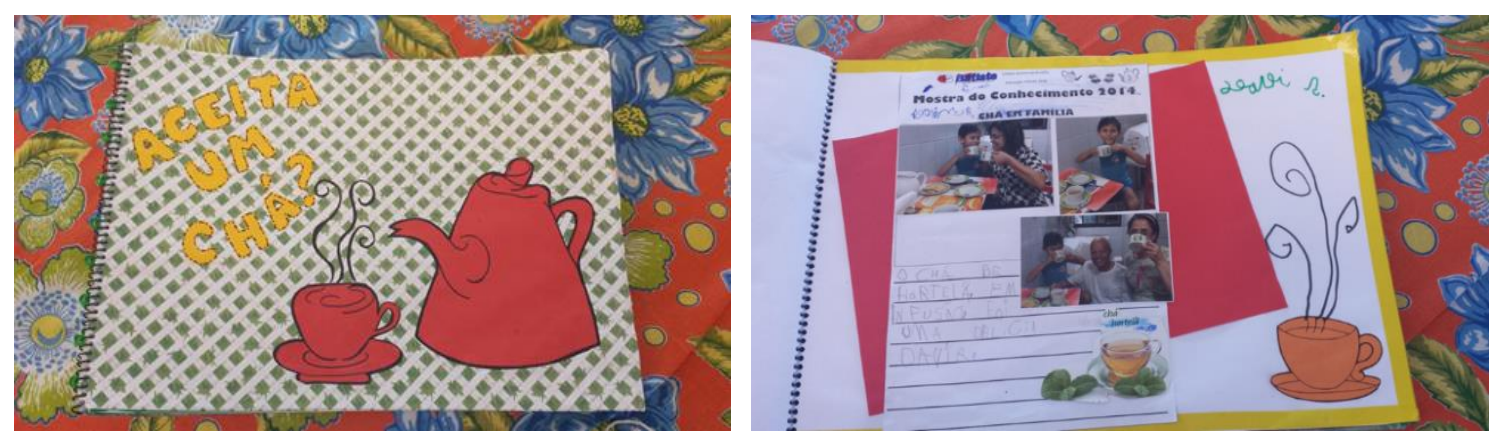

Figuras 9 e 10: Capa do livro elaborado pelas professoras da escola com relato das experiências dos alunos; livro aberto com fotos de uma criança tomando chá com a família.

Nos estudos que foram abordados neste trabalho, percebe-se como ponto em comum o empenho dos educadores em uma abordagem didática, contextualizada a situação local e inclusiva à comunidade. Como resposta, as crianças se mostram motivadas diante das atividades propostas, participam por meio de questionamentos e comparam as vivências em sala de aula com fatos do seu ambiente familiar.

Dal Soto (2013), ao perceber a resposta das crianças diante das atividades desenvolvidas conclui: "Em todos os momentos, nos desenhos, nas interações com os colegas e o meio natural, nas falas e atitudes espontâneas, ficaram evidentes as construções de conhecimento, que resultaram do trabalho desenvolvido." Ao cultivarem as plantas, aprenderam sobre os cuidados necessários à preservação da vida e sobre as relações destas com os demais seres da Natureza (DAL SOTO, 2013). 


\section{RESULTADOS E DISCUSSÃO}

Segundo Oliveira e Akissue (1998), a botânica ensinada nos cursos de farmácia deve ser orientada no sentido de sua aplicação. Deve fornecer subsídios que permitam conhecer adequadamente as plantas medicinais e as drogas com elas elaboradas, plantas tóxicas e plantas utilizadas na alimentação visto que é dever do farmacêutico, orientar a comunidade quanto à utilização das plantas medicinais.

Comparada com a dos medicamentos usados nos tratamentos convencionais, a toxicidade de plantas medicinais e fitoterápicos pode parecer trivial, isto entretanto, não é verdade (LORENZI e MATOS, 2008; VEIGA JUNIOR et al., 2005). A toxicidade de plantas medicinais é um problema sério de saúde pública. Os efeitos adversos dos fitomedicamentos, possíveis adulterações e toxidez, bem como a ação sinérgica (interação com outras drogas) ocorrem comumente (VEIGA JUNIOR et al.,2005).

$\mathrm{Na}$ educação infantil, o ensino de ciências deve orientar as crianças quanto aos benefícios e riscos da utilização de plantas medicinais utilizando-se de instrumentos como hortas medicinais, jardins sensoriais e a prática do herbário, possibilitando que a criança tenha acesso as características morfológicas e fisiológicas das plantas, aonde ela possa tocar, manipular, sentir o cheiro e verificar o tipo de ambiente que as espécies melhor se adaptam na natureza (PRICHULA, 2011).

A prática do herbário e elaboração de exsicatas pode vir também a ser utilizada como alternativa a falta de um ambiente natural em que a criança tenha contato com a planta in natura, permitindo que ela possa ter acesso a esse material dentro da sala de aula.

Mas, apesar da grande contribuição dos herbários e sua importância educacional, eles se encontram muitas vezes em instituições aonde apenas pesquisadores podem ter acesso às coleções, ficando fechadas ao público leigo. Assim, apresentar aos alunos, por meio da proposta de aula prática do herbário escolar como estas instituições funcionam, é uma oportunidade única de aprendizado (OTA, 2012). 
Outra forma de se conhecer essas coleções botânicas se dá pelo acesso aos herbários virtuais. A maioria dos herbários brasileiros e alguns do exterior estão vinculados ao Instituto Nacional de Ciência e Tecnologia- INCT Herbário Virtual da Flora e dos Fungos, criado em 2008. São disponibilizados on line imagens das exsicatas além de outros dados e informações sobre os herbários que estão vinculados a rede, pelo Sistema de Informação distribuído para Coleções, o speciesLink/CRIA (INCT, 2013).

Faculdade de Educação da Universidade de Brasília, disponibiliza para toda a sociedade este ambiente virtual de divulgação científica.

A criação em 2006 do Museu Virtual de Ciência e Tecnologia da Universidade de Brasília também objetiva tornar acessível conteúdos de natureza científica à comunidade pelo acesso ao seu site. O museu está vinculado a Faculdade de Educação- FE da UnB e o seu material é produzido nessa universidade por seus pesquisadores, professores e alunos com missão de fomentar o interesse pela Ciência, despertar vocações e subsidiar professores em relações educativas que abordam esses conteúdos (SANTOS, 2006).

Em 2017, também pela FE- UnB, foi desenvolvido o "Museu do Cerrado" que permite tanto o acesso virtual como a inclusão de diversos materiais científicos sobre o Cerrado pela comunidade. O museu tem como missão divulgar através do seu espaço aberto conteúdos audiovisuais, bibliográficos, artísticos e pedagógicos produzidos para a preservação e recuperação do Cerrado, difundindo os saberes populares e os conhecimentos científicos acerca dessa sociobiodiversidade (CORRÊA, 2017).

Uma forma de se transmitir esses conhecimentos científicos na escola se dá pela alfabetização cientifica, que permite as crianças se familiarizarem com o ambiente natural, relacionando-o com a sua vida. A construção da alfabetização científica torna-se significativa ao passo que a criança percebe os ambientes e as situações cotidianas como fontes de conhecimento, a partir da curiosidade, criação de hipóteses, experimentações e conclusões sobre diferentes fenômenos (LOMEU e IOCCA, 2016). 
Segundo Chassot (2003), citado por Lomeu e locca (2016), a iniciação às ciências junto às crianças de Educação Infantil pode desvendar um mundo brilhante aos olhos dos pequeninos, pois essa é a fase das descobertas, cujas primeiras atividades sobre a alfabetização científica poderão ser desenvolvidas vivenciando um "processo pelo qual elas serão capazes de saber ler a linguagem em que está escrita a natureza”.

Esse processo de compreensão da natureza a partir dos olhares das crianças é visto nos estudos aqui apresentados que mesmo tendo sido realizados em diferentes contextos educacionais, apresentam semelhanças nos resultados que foram obtidos com as atividades propostas.

As crianças se identificaram com os aspectos da natureza ao seu redor à medida que iam descobrindo cada vez mais esse ambiente e se mostraram motivadas a participar das atividades que foram elaboradas por serem lúdicas e significativas para elas.

Foi demonstrado que por meio de algumas atitudes simples e de baixo custo, porém, que implicam disposição por parte dos educadores na sua elaboração, se alcança uma melhoria no processo de aprendizagem, permitindo uma nova percepção sobre a temática das plantas medicinais.

Com a elaboração de um herbário lúdico, além de se ter um processo de baixo custo e reproduzível para o ensino da biodiversidade local, a aprendizagem ocorre de maneira que a criança possa ter contato com o objeto de estudo e ter seus sentidos estimulados assim como sua criatividade. 


\section{CONCLUSÃO}

O presente estudo proporcionou o contato com diferentes formas de abordagem no ensino das plantas medicinais em diferentes contextos culturais e econômicos: escolas pública e particular, escolas rural e indígena, presentes em locais diversos do Brasil. Isto demonstra quão grande é o nosso país em termos de riquezas naturais e culturais e quão rica pode ser a aprendizagem sobre plantas medicinais na educação infantil quando esta se faz de forma lúdica, com os mais diversos recursos que muitas vezes são conseguidos a um baixo custo. Assim ocorre com a utilização de um herbário que possibilite à criança tocar e perceber as diferenças entre as espécies, proporcionando a promoção desse conhecimento e a valorização da natureza.

Como profissionais farmacêuticos, cabe a responsabilidade em orientar a comunidade e divulgar esses conhecimentos para que o ensino de plantas medicinais seja a realidade também das crianças e proporcionar que elas plantem e façam brotar novos jardins medicinais que possam vir a remediar os males que são causados ao nosso planeta. 


\section{REFERÊNCIAS BIBLIOGRÁFICAS}

AKONTEH, S.W.D.; SOUZA, S. R. Meu primeiro herbário: descobrindo as plantas medicinais. In: XXIV SIMPÓSIO DE PLANTAS MEDICINAIS DO BRASIL, Belo Horizonte, MG, 21 a 24 de set. 2016 .

AMBROSE, D. C. P. et. al. Leafy Medicinal Herbs: Botany, Chemistry, Postharvest Technology and Uses. CABI, 2016.

AMOROZO, M. C. M. Sistemas agrícolas de pequena escala e a manutenção da agrobiodiversidade - uma revisão e contribuições. Rio Claro, SP: Edição do autor; Botucatu: FCA - UNESP, 2013.

BEZERRA, A. C. G. Escola Vivência Infantil, Lazer e Aprendizagem (Vila): experiência de educação integral. Em Aberto, v. 25, n. 88, 2012.

BFG. The Brazil Flora Group. Growing knowledge: an overview of Seed Plant diversity in Brazil. Rodriguésia, Rio de Janeiro, v. 66, n. 4, p. 1085-1113, 2015.

BRASIL. ANVISA. Formulário de Fitoterápicos da Farmacopéia Brasileira / Agência Nacional de Vigilância Sanitária. Brasília: Anvisa, 2011. 126p.

BRASIL. EMBRAPA. Plantas medicinais nos biomas brasileiros. Embrapa Recursos Genéticos e Biotecnologia-Folderes/Folhetos/Cartilhas (INFOTECA-E), 2010.

BRASIL. Ministério da Educação e do Desporto. Secad. Educação Ambiental. Disponível em: http://portal.mec.gov.br/expansao-da-rede-federal/194-secretarias- 
112877938/secad-educacao-continuada-223369541/13637-educacao-ambiental 2017>Acesso em 27 out. 2017.

BRASIL, Ministério da Educação. Conselho Nacional de Educação. Diretrizes Curriculares Nacionais da Educação Infantil. Parecer 20/09 e Resolução 05/09. Brasilia: MEC, 2009.

BRASIL. Ministério da Saúde. Secretaria de Ciência, Tecnologia e Insumos Estratégicos. Departamento de Assistência Farmacêutica. Política nacional de plantas medicinais e fitoterápicos / Ministério da Saúde, Secretaria de Ciência, Tecnologia e Insumos Estratégicos, Departamento de Assistência Farmacêutica. - Brasília: Ministério da Saúde, 2006.60 p. - (Série B. Textos Básicos de Saúde)

BRASIL. Ministério da Saúde. Secretaria de Ciência, Tecnologia e Insumos Estratégicos. Departamento de Assistência Farmacêutica e Insumos Estratégicos. Programa Nacional de Plantas Medicinais e Fitoterápicos / Ministério da Saúde, Secretaria de Ciência, Tecnologia e Insumos Estratégicos, Departamento de Assistência Farmacêutica e Insumos Estratégicos. - Brasília : Ministério da Saúde, 2009. 136 p. : il. - (Série C. Projetos, Programas e Relatórios)

BRASIL. Ministério da Saúde. Secretaria de Atenção à Saúde. Departamento de Atenção Básica. Práticas integrativas e complementares: plantas medicinais e fitoterapia na Atenção Básica/Ministério da Saúde. Secretaria de Atenção à Saúde. Departamento de Atenção Básica. - Brasília : Ministério da Saúde, 2012. 156 p. : il. - (Série A. Normas e Manuais Técnicos) (Cadernos de Atenção Básica ; n. 31)

BRASIL. Resolução CD/FNDE $\mathrm{n}^{\circ}$ 18, de 21 de maio de 2013. Manual Escolas Sustentáveis. 2013. 
BRAZ, N. C. S. ; LEMOS, J. R. " Herbário Escolar" como instrumento didático na aprendizagem sobre plantas em uma escola de ensino médio na cidade de Parnaíba, Piauí. Revista Didática Sistêmica, v. 16, n. 2, p. 3-14, 2015.

CALIXTO, J. B. Biodiversidade como fonte de medicamentos. Ciência e Cultura, São Paulo, v. 55, n. 3, p. 37-39, Set. 2003.

CAMPOS, S. C. et al. Toxicidade de espécies vegetais. Revista Brasileira de Plantas Medicinais, 2016.

CARMO, J. D. O. et. al. Herbário escolar de plantas medicinais como ferramenta na aprendizagem de botânica. In: $64^{\circ}$ CONGRESSO NACIONAL DE BOTÂNICA DE BELO HORIZONTE. Belo Horizonte, 10-15 de nov. 2013.

CINTRA, M. O. Botânica para os sentidos: preposição de plantas para elaboração de um jardim sensorial. (Monografia). Faculdade de Ciências da Educação e Saúde - FACES/ UniCEUB. Brasília, 2014.

CORRÊA, R. A. Museu do cerrado. 2017. Disponível em: <museucerrado.esy.es> Acesso em: 12 dez. 2017

CORRÊA JÚNIOR, C.; SCHEFFER, M. C. Boas Práticas Agrícolas (BPA) de Plantas Medicinais, Aromáticas e Condimentares. Curitiba: Instituto Emater, 2013. 52 p.: il., (Série Informação Técnica, n. 88) ISBN: 978-85-63667-32-8 
DAL SOTO, D. V. Por uma educação planetária: Produzindo sentidos e significados às práticas pedagógicas na educação infantil. Monografias Ambientais, v. 11, n. 11, p. 2426-2434, 2013.

FAGUNDES, J. A.; GONZALEZ, C. E. F. Herbário escolar: suas contribuições ao estudo da Botânica no Ensino Médio. Programa de Desenvolvimento Educacional da Secretaria de Estado da Educação. (Mestrado). Universidade Tecnológica Federal do Paraná, p. 1675-8, 2006.

FENG, L. Y.; FERRANTE, V. L. S. B. Projeto Educação do Campo: estratégias e alternativas no campo pedagógico. Retratos de Assentamentos, v. 11, n. 1, p. 195-224, 2008

FOGLIO, M. A. et al. Plantas medicinais como fonte de recursos terapêuticos: um modelo multidisciplinar. Construindo a história dos produtos naturais, v. 7, p. 1-8, 2006.

FREIRE, P. Educação e mudança. Editora Paz e terra, 2007.

GONZATTI, F.; SCUR, L.; SCOPEL, J. M. Integração do Herbário da Universidade de Caxias do Sul nos programas de Educação Ambiental da Universidade de Caxias do Sul. UNISANTA. BioScience, v. 6, n. 5, - Edição Especial. p. 55-61, 2017.

INCT. Manual de Procedimentos para herbários. INCT-Herbário virtual para a Flora e os Fungos. Editora Universitária UFPE, Recife, 2013.

LOMEU, G. C.; IOCCA, F. A. D. S. Alfabetização científica na educação infantil em uma escola do campo. Eventos Pedagógicos. Número Regular: Experiências em Educação do Campo: perspectivas e práticas pedagógicas, v. 7, n. 3, p. 1402-1414, 2016. 
LORENZI, H.; MATOS, F. J. A. Plantas medicinais no Brasil: nativas e exóticas, 2ed. Instituto Plantarum, Editora Nova Odessa, SP, 2008. 544 p.

MALDANER, M. P. Educação e cultura indígena guarani: práticas educacionais no Colégio Estadual Indígena Teko Ñemoingo, Tekoha Ocoy. Dissertação (Mestrado) Universidade Federal da Integração Latino- Americana. Foz do Iguaçu, Paraná, 2016.

MENTZ, L. A.; BORDIGNON, S. A. L. Nomenclatura botânica, classificação e identificação de plantas medicinais. In: SIMÕES, C. M. O. et al. Farmacognosia: da planta ao medicamento. 5. ed. Porto Alegre: UFSC, 2003. 1102 p.

LOUREIRO, J. O.; DAL-FARRA, R. A. O ensino de botânica nos primeiros anos do Ensino Fundamental utilizando desenhos e herbários. In: X ENCONTRO NACIONAL DE ENSINO DE CIÊNCIAS., Águas de Lindóia, 2015.

LOURENÇO, F. S. ; BRITO JÚNIOR, F. P. Semeando agroecologia em creche escolar. Nexus-Revista de Extensão do IFAM, v. 3, n. 1, 2017.

NUNES, M. J. M. et al. Herbário didático como ferramenta diferenciada para a aprendizagem em uma escola de ensino médio em Parnaíba, Piauí. Momento-Diálogos em Educação, v. 24, n. 2, p. 41-56, 2016.

OLIVEIRA, F.; AKISUE, G. Fundamentos de Farmacobotânica. 1 ed. São Paulo: Atheneu, 1998. 
OTA, M. D.'A. Herbário escolar: uma proposta de atividade prática para o ensino de botânica. (Monografia). Faculdade de Educação e Artes da Universidade do Vale do Paraíba. São José dos Campos, SP, 2012.

PAIXÃO, J. L. F.; HUMBERTO, D.; OLIVEIRA, J. E. Z. E. Horta orgânica de ervas medicinais: inclusão social na comunidade da Barra em Muriaé/MG - Brasil. Revista Agrogeoambiental, Pouso Alegre, v. 5, n. 2, caderno II, p.19-30, ago. 2013.

PINILLOS, M. A.et al. Intoxicación por alimentos, plantas y setas. Anales del Sistema Sanitario de Navarra, v.26, n.1, p. 243-263, 2003.

POLHASTO, S. S. A prática da Ecopedagogia e suas possibilidades. (monografia). Educação Ambiental, 2017.

PRICHULA, J. Vamos para o pátio?: aprendendo Ciências Naturais através de oficinas lúdicas. (Monografia). 2011.

RIZZINI, C.T.; MORS, W.B. Botânica econômica brasileira. São Paulo, EPUSP, 1976. 207 p.

SANTOS, G.L. Museu Virtual de Ciência e Tecnologia da Universidade de Brasília. 2006. Disponível em < http://www.museuvirtual.unb.br/index.htm> Acesso em: 17 dez. 2017

SANTOS, M. C. F. O herbário como material didático para o ensino de Ciências e Biologia. Pp. 292-295. In: II ENCONTRO REGIONAL E ENSINO DE BIOLOGIA: FORMAÇÃO DE PROFESSORES DE BOOLOGIA: ARTICULANDO UNIVERSIDADE E ESCOLA. Niterói, SBEnBio-Regional 02. 2003. 
SINITOX. Dados de Intoxicação: dados nacionais. Sistema Nacional de Informações Tóxico-Farmacológicas. SINITOX. Disponível em <https://sinitox.icict.fiocruz.br/dadosnacionais>Acesso: em 20 set. 2017.

SOUSA, B. M. N. C. Percepção de crianças sobre plantas medicinais em ambiente escolar de educação infantil e ensino fundamental em Florianópolis, SC. (Monografia). Centro de Ciências Agrárias da Universidade Federal de Santa Catarina, Florianopólis, 2013.

SOUZA, S. R., et al. Projeto chá com prosa e cheiro do saber. In: Semana Universitária 2014: Aonde a UnB que você vê pode te levar. Universidade de Brasília, 2014.

STACE C.A. Plant taxonomy and biosystematics. London. Edward Arnold, 1980.

TAVARES, E. O. et al .Fatores associados à intoxicação infantil. Universidade Federal do Rio de Janeiro. Escola Anna Nery Revista de Enfermagem, v.17, n.1, p.31-37, 2013.

UNESCO, 2005. Década da Educação das Nações Unidas para um Desenvolvimento Sustentável, 2005-2014: documento final do esquema internacional de implementação. Edição publicada pelo Escritório da UNESCO no Brasil. Brasília. 120p. Título original: United Nations Decade of Education for Sustainable Development 2004-2005 - Draft International Implementation Scheme.

VEIGA JUNIOR, V. F. et al. Plantas medicinais: cura segura. Química nova, v. 28, n. 3, p. 519-528, 2005. 
